\title{
INEFICACIA DE LA RELACIÓN DE FILIACIÓN ENTRE EL PROGENITOR INTENCIONAL Y EL NIÑO NACIDO A TRAVÉS DEL RECURSO A LA GESTACIÓN POR SUSTITUCIÓN POR CONTRARIEDAD AL ORDEN PÚBLICO EN EL ORDENAMIENTO ITALIANO
}

\author{
INEFFECTIVENESS OF THE FILIATION RELATIONSHIP \\ BETWEEN THE INTENTIONAL PARENT AND THE CHILD \\ BORN BY SURROGACY DUE TO VIOLATION OF PUBLIC \\ ORDER IN THE ITALIAN LEGAL SYSTEM
}

\author{
Elisabetta MazzILli \\ Profesor Ayudante Doctor \\ Universidad Pública de Navarra
}

Recibido: 15.06.2021 / Aceptado: 09.07.2021

DOI: https://doi.org/10.20318/cdt.2021.6313

\begin{abstract}
Resumen: El reconocimiento en el ordenamiento italiano de la eficacia de la resolución judicial extranjera que haya establecido la relación de filiación entre un menor nacido en el extranjero mediante el recurso a la gestación por sustitución y el progenitor intencional no biológico de nacionalidad italiana, encuentra un obstáculo en la prohibición de la maternidad subrogada prevista en el art. 12.6 de la ley 40/2004, que la Corte de Casación italiana, en Secciones Unidas, ha calificado como principio de orden público, prevaleciente sobre el interés del menor. La Corte Constitucional, considerando el papel que juega el principio del interés superior del menor, en aras de conservar el status filiationis legítimamente adquirido en el extranjero, ha moderado recientemente esta posición.
\end{abstract}

Palabras clave: gestación por sustitución, maternidad subrogada, orden público, interés superior del menor, progenitor intencional.

Abstract: Recognition in the Italian legal system of the effectiveness of the foreign judicial decision that has established the relationship of filiation between a minor born abroad through surrogacy and the intentional non-biological parent of Italian nationality, finds an obstacle in the prohibition of maternity subrogation provided for in art. 12.6 of law 40/2004, that the Italian Court of Cassation on United Sections has qualified as a principle of public order, prevailing over the interest of the minor. The Constitutional Court, considering the role played by the principle of the best interests of the minor, in order to preserve the filiation status legitimately acquired abroad, has recently moderated this position.

Keywords: surrogacy, maternity surrogacy, public order, best interests of the minor, intentional parent.

Sumario: I. Consideraciones introductorias. II. El límite de la contrariedad al orden público y el concepto jurisprudencial de orden público internacional. III. La cuestión de la prohibición de la maternidad subrogada contenida en el art. 12.6 de la ley 40/2004 como norma de orden público. IV. El juicio de la Corte Constitucional sobre el interés del menor. 1. Génesis y objeto del juicio de le- 
gitimidad constitucional. 2. Los argumentos de la Corte de Casación en contra del "diritto vivente". 3. La decisión de la Suprema Corte Constitucional y sus fundamentos. V. Consideraciones críticas. 1. Las cuestiones controvertidas. 2. La individuación del concepto de orden público internacional y el "diritto vivente". 3. El interés superior del menor en el caso concreto. 4. El balance del interés superior del menor con los demás derechos fundamentales. 5. La cuestión del status filiationis del niño. 6. La existencia de una relación paternofilial de facto entre el progenitor intencional y el menor.

7. Los límites de la "adopción en casos particulares". VI. Conclusiones.

\section{Consideraciones introductorias}

1. El reconocimiento en el ordenamiento italiano de la relación de filiación entre el progenitor intencional no biológico y el niño nacido en el extranjero por gestación subrogada pasa a través de la consideración del concepto de orden público internacional y de su alcance, sobre todo en relación con su idoneidad para incidir en los derechos fundamentales del niño.

En particular, se ha discutido en la jurisprudencia acerca de la posibilidad de que la prohibición de la gestación subrogada constituya un principio de orden público internacional apto para justificar la denegación de la transcripción del acta de nacimiento del menor, legítimamente formada en el extranjero.

En este contexto, se ha otorgado una notable atención al papel que debe desenvolver el principio del interés superior del menor, en aras de otorgar al nacido por gestación subrogada el grado de tutela más adecuado para poder garantizarle la conservación de su status filiationis legítimamente adquirido en el extranjero, y evitarle así las posibles violaciones de su vida personal y familiar, y de su identidad social.

Además, se ha abordado el tema de las soluciones alternativas a la transcripción del acta de nacimiento en el Registro civil, como el sistema de "adopción para casos particulares", regulado en el art. 44.1 d) de la Ley 184/1983, con sus pros y sus contras.

\section{El límite de la contrariedad al orden público y el concepto jurisprudencial de orden público internacional}

2. Según el art. 64.1.g) de la Ley $218 / 1995^{1}$ de "Riforma del sistema italiano di diritto internazionale privato", la sentencia extranjera es reconocida automáticamente en Italia cuando sus disposiciones no producen efectos contrarios al orden público. El art. 65 del mismo texto legal establece que surtirán efecto en Italia las medidas extranjeras relativas a la capacidad de las personas y la existencia de relaciones familiares o de los derechos de la personalidad cuando hayan sido pronunciadas por las autoridades del Estado extranjero "siempre que no sean contrarias al orden público" y se hayan respetado los derechos esenciales de la defensa.

Asimismo, el art. 18 del Decreto del Presidente della Repubblica (d.P.R.) 396/2000 "Regolamento per la revisione e la semplificazione dell'ordinamento dello stato civile, a norma dell'articolo 2, comma 12, della legge 15 maggio 1997, n. 127'”2, establece que no podrán inscribirse en los registros del estado civil italiano los actos constituidos en el extranjero cuando éstos sean contrarios al orden público.

3. El concepto de orden público ha sido identificado por la Corte de Casación italiana con el «conjunto de los principios fundamentales que caracterizan el ordenamiento interno en un determinado

\footnotetext{
1 "Legge 31 maggio 1995, n. 218: Riforma del sistema italiano di diritto internazionale privato", Gazzetta Ufficiale, Serie Generale, núm. 128 de 3 junio 1995 (Suppl. Ordinario n. 68).

${ }^{2}$ D.P.R.396/2000, Gazzetta Ufficiale, Serie Generale, núm. 303 de 30 diciembre 2000 (Suppl. Ordinario n. 223). Entrada en vigor del decreto: 30 marzo 2001.
} 
periodo histórico, inspirados en exigencias de tutela de los derechos fundamentales del hombre comunes a distintos ordenamientos y colocados en un nivel superior al de la legislación ordinaria» ${ }^{3}$.

Según la Corte, los principios de orden público que se erigen como limitación a la aplicación de leyes extranjeras no coinciden con las normas imperativas del ordenamiento interno, puesto que estos principios no pueden ser extraídos exclusivamente del marco normativo interno, sino que deben derivarse de exigencias de garantía y de tutela de derechos fundamentales, o de valores fundantes de la entera estructura del ordenamiento jurídico ${ }^{4}$. De hecho, no puede individuarse un contraste con el orden público por el sólo hecho de que la norma extranjera sea discordante en su contenido con una o más disposiciones del derecho nacional, pues el parámetro de referencia no está constituido por las normas con las que el legislador ordinario ejercita su discrecionalidad en un determinado ámbito, sino exclusivamente por los principios fundamentales vinculantes para el mismo legislador ordinario.

En este contexto, los Tribunales, que tienen el deber de verificar previamente la compatibilidad de la norma extranjera con esos principios, deberán negar el conflicto con el orden público si se trata de una mera incompatibilidad temporánea de la norma extranjera con la legislación nacional vigente, cuando esta representa una de las posibles formas de expresión de la discrecionalidad del legislador ordinario en un determinado momento histórico ${ }^{5}$.

4. La misma Corte de Casación en Secciones Unidas ${ }^{6}$ se ha inclinado más recientemente ${ }^{7}$ hacia una noción de orden público que comprende no sólo los principios fundamentales constitucionalmente garantizados y los consagrados en las fuentes internacionales y supranacionales, sino también la manera en que los mismos han encontrado actuación en la ley ordinaria y en la interpretación proporcionada por la jurisprudencia constitucional y ordinaria. En particular, para la identificación del contenido del orden público, entendido como conjunto de valores fundantes del ordenamiento jurídico en un determinado momento histórico, habrá que recurrir a la normativa ordinaria, entendida como instrumento de actuación de los valores consagrados en la Constitución, y a la obra de interpretación, síntesis y recomposición llevada a cabo por la jurisprudencia, tanto constitucional como ordinaria, a través de la cual se ha llegado a la extrapolación de los principios fundamentales del ordenamiento jurídico.

Este trabajo hermenéutico de los Tribunales se articula sobre la base no sólo de los solemnes enunciados de la Carta Constitucional y de los Convenios y Declaraciones internacionales, sino también de la ley ordinaria, y constituye el llamado "diritto vivente".

\section{La cuestión de la prohibición de la maternidad subrogada contenida en el art. $\mathbf{1 2 . 6}$ de la ley 40/2004 como norma de orden público}

5. Respecto de la cuestión de la prohibición de la maternidad subrogada, la orientación de la jurisprudencia de legitimidad ha sido la de asignar a la ley 40/2004 ("Norme in materia di procreazione

\footnotetext{
${ }^{3}$ Cfr. Cass., Secc. I, 30 septiembre 2016, núm. 19599.

${ }^{4}$ Cfr. Cass., Secc. III, 22 agosto 2013, núm. 19405; Cass., Secc. "lavoro”, 19 julio 2007, núm. 16017.

${ }^{5}$ Cfr. Cass., Secc. I, 30 septiembre 2016, núm. 19599.

${ }^{6}$ Las Secciones simples están flanqueadas por las Secciones Unidas, que constituyen un cuerpo colegiado con la tarea de resolver las controversias que han surgido en las Secciones simples cuando se trata de cuestiones particulares de máxima importancia. El número de miembros es de cinco magistrados para las secciones simples y nueve para las Secciones Unidas.

${ }^{7}$ Cfr. Cass., Secc. Unidas, 8 mayo 2019, núm. 12193.

${ }^{8}$ Profundizan en el concepto de "diritto vivente", entre otros, G. ALPA, "Il diritto giurisprudenziale e il diritto «vivente» - Convergenza o affinità dei sistemi giuridici?", en Sociologia del diritto, 2008, p. 47; A. Anzon, "Il giudice a quo e la Corte costituzionale tra dottrina dell'interpretazione conforme a costituzione e dottrina del diritto vivente (nota a Corte cost., 23 aprile 1998, n. 138)", en Giurisprudenza costituzionale, 1998, p. 1082; ID., "La Corte costituzionale e il diritto vivente", en Giurisprudenza costituzionale, 1984, I, p. 300; F. CARNELUTTI, "Giurisprudenza consolidata (ovvero della comodità del giudicare)", en Rivista di diritto processuale, 1949, I, p. 41; M. CомBA, "La Corte costituzionale tra diritto vivente e diritto in embrione", en Giurisprudenza italiana, 1992, I, 1, p. 396; V. Marinelli, Studi sul diritto vivente, Jovene, Napoli, 2008; F. SANToro Passarelli, "A proposito del diritto vivente", en Iustitia, 1993, p. 54.
} 
medicalmente assistita"), con particular referencia a su artículo 12.6 que contiene la prohibición en cuestión ${ }^{9}$, una función esencial de tutela de intereses constitucionalmente relevantes.

6. La sentencia de la Corte de Casación núm. $24001 / 2014^{10}$ sostiene que el orden público internacional es el "límite que el ordenamiento nacional pone a la entrada de normas y medidas extranjeras, para la protección de su coherencia interna" y que este límite "no puede reducirse únicamente a los valores compartidos por la comunidad internacional, sino que incluye también unos principios y valores exclusivamente propios, siempre que sean fundamentales y por lo tanto irrenunciables". Dicha sentencia ha considerado pacífica la aplicabilidad de la prohibición de la maternidad subrogada resultante del art. 12.6 de la Ley 40/2004, observando que dicha disposición es sin duda de orden público, debido a que para su violación se prevé una sanción penal, y por regla general las sanciones penales se establecen en defensa de bienes fundamentales.

7. Según la Corte, asumen relevancia en este contexto la dignidad humana de la mujer embarazada, que es constitucionalmente tutelada, y la adopción, con la cual la maternidad subrogada está en conflicto, puesto que el ordenamiento jurídico confía la realización de proyectos de paternidad sin vínculos biológicos con el nacido exclusivamente al instituto de la adopción, regido por normas especiales que protegen a todos los interesados, en primer lugar a los menores, y no por el mero acuerdo de las partes.

Y más importante aún, la Corte ha excluido que dicha prohibición esté en conflicto con el interés superior del menor, tutelado por el art. 3 del Convención de Nueva York sobre los derechos del niño ${ }^{11}$, considerando que el legislador, en el ámbito de su discrecionalidad, ha razonablemente elegido que el interés superior del menor se realice especialmente atribuyendo la maternidad a la parturienta y confiando a la institución de la adopción, realizada con las garantías propias del procedimiento judicial, más que el simple acuerdo de las partes, la realización de una paternidad separada del vínculo biológico.

8. La Corte de Casación, en Secciones Unidas, ha afirmado en la más reciente sentencia de 8 de mayo de 2019, núm. $12193^{12}$, que el reconocimiento de la eficacia de la resolución judicial extranjera con la que se ha establecido la relación de filiación entre un menor nacido en el extranjero mediante el recurso a la gestación por sustitución y el progenitor intencional no biológico de nacionalidad italiana, encuentra un obstáculo en la prohibición de la gestación por sustitución prevista en el art. 12.6 de la ley 40/2004, precepto que se califica como principio de orden público, puesto que protege valores fundamentales, como la dignidad humana de la mujer embarazada y el instituto de la adopción.

9. Estos valores se consideran como prevalentes respecto del interés del menor, en el marco de un balance efectuado directamente por el legislador, que el juez no puede sustituir con su apreciación.

Se trata, por lo tanto, de una prohibición que expresa un principio superior de orden público que, como también había aclarado la Corte Constitucional en la sentencia 272/2017 práctica que "ofende de manera intolerable la dignidad de la mujer" ${ }^{14}$ y se refiere, por tanto, a valores superiores y fundamentales.

De ahí que no se pueda transcribir ni reconocer en Italia la resolución judicial extranjera que, admitiendo implícitamente la validez del acuerdo de gestación por sustitución, atribuye la paternidad (o la maternidad) incluso al progenitor intencional que no ha aportado contribución biológica alguna a la procreación.

\footnotetext{
${ }^{9} \mathrm{El}$ citado artículo establece lo siguiente: "Chiunque, in qualsiasi forma, realizza, organizza o pubblicizza la commercializzazione di gameti o di embrioni o la surrogazione di maternità è punito con la reclusione da tre mesi a due anni e con la multa da 600.000 a un milione di euro".

${ }^{10}$ Cass., Secc. I, 11 noviembre 2014, núm. 24001.

${ }^{11}$ Convención de Nueva York sobre los derechos del niño de 20 de noviembre de 1989, que se ejecutó en Italia con la Ley núm. 176, de 27 de mayo de 1991.

${ }^{12}$ Cass., Secc. Unidas, 8 mayo 2019, núm. 12193, cit.

${ }^{13}$ Corte Cost., sent. 272/2017, Gazzetta Ufficiale de 20 diciembre 2017, núm. 51.

${ }^{14}$ Literalmente.: "pratiche vietate dalla legge, quale è la maternità surrogata, che offende in modo intollerabile la dignità della donna e mina nel profondo le relazioni umane".
} 
10. Esta conclusión, según las Secciones Unidas, no se plantea en contraste con el interés superior del menor: porque ese interés no tiene valor absoluto y puede disminuir con respecto a otros valores. Esta valoración equilibrada también forma parte del margen de apreciación que el Tribunal Europeo de Derechos Humanos (en adelante, TEDH) reconoce a los Estados a la hora de decidir si autorizar o no la práctica de la gestación por sustitución y los efectos jurídicos relacionados con ella. Además, el interés del menor a permanecer en la pareja (incluso del mismo sexo) a la que pertenece el padre de intención todavía puede ser protegido mediante la "adopción para casos particulares" regulada en el art. 44.1 d) de la Ley 184/1983, según la orientación jurisprudencial inaugurada por la Corte de Casación ya en $2016^{15}$.

A la luz de esta reconstrucción, las Secciones Unidas han concluido que los efectos del reconocimiento de la medida judicial extranjera, cuya transcripción se solicita, entran en conflicto con el orden público, por aplicación del art. $64.1 \mathrm{~g}$ ) de la ley 218/1995.

10. La jurisprudencia constitucional, por su parte, también considera que el art. 12.6 de la Ley 40/2004 es el resultado de un equilibrio de intereses aplicado por el propio legislador. De hecho, la Corte Constitucional italiana ha reconocido en la ley 40/2004 una normativa "constitucionalmente necesaria", observando que representa la primera disciplina orgánica relativa a un sector delicado y que implica una pluralidad de intereses constitucionales importantes que, en su conjunto, exigen buscar un equilibrio entre ellos, que garantice un nivel mínimo de protección legislativa ${ }^{16}$.

\section{El juicio de la Corte Constitucional sobre el interés del menor}

\section{Génesis y objeto del juicio de legitimidad constitucional}

11. La Sección Primera Civil de la Corte de Casación, con ordenanza del 29 de abril de $2020^{17}$, propuso un juicio de legitimidad constitucional del art. 12.6 de la ley 40/2004 ("Norme in materia di procreazione medicalmente assistita"), del art. 64.1.g de la ley 218/1995 ("Riforma del sistema italiano di diritto internazionale privato") y del art. 18 del d.P.R. 396/2000 ("Regolamento per la revisione e la semplificazione dell'ordinamento dello stato civile, a norma dell'articolo 2, comma 12, della legge 15 maggio 1997, n. 127"), en la parte en que, según la interpretación actual del "diritto vivente", no permiten el reconocimiento y la ejecución, por motivos de orden público, de la medida judicial extranjera relativa a la inclusión del progenitor de intención no biológico en el acta de estado civil de un menor procreado según las modalidades de la gestación por sustitución.

La Corte de Casación quiso poner en tela de juicio el "diritto vivente" resultante de la mencionada Sentencia en Secciones Unidas núm. 12193/2019, sobre todo en relación con la atribución a la prohibición de la técnica de la gestación por sustitución de la consideración de principio de orden público internacional, prevaleciente, a priori, sobre el interés del menor a mantener su status filiationis.

\section{Los argumentos de la Corte de Casación en contra del "diritto vivente".}

12. La Corte de Casación ha evidenciado como la actual configuración del "diritto vivente", tras la intervención de las Secciones Unidas, en la parte en que no permite el reconocimiento de una resolución judicial extranjera que declare la relación de filiación de un menor nacido por gestación subrogada con su progenitor intencional no biológico, resulta en contraste con los derechos inviolables del menor, tutelados por la Constitución, los Convenios internacionales y la legislación europea.

\footnotetext{
${ }^{15}$ Cass., Secc. I. 22 junio 2016, núm. 12962.

${ }^{16}$ Cfr. Corte Cost., sent. 45/2005, Gazzetta Ufficiale de 2 febrero 2005, núm. 5; v. también sent. 162/2014, Gazzetta Ufficiale de 18 junio 2014, núm. 2613 y sent. 151/2009, Gazzetta Ufficiale de 13 mayo 2009, núm. 19.

${ }^{17}$ Cfr. Corte Cost., Ordinanza núm. 35 de 2020, Gazzetta Ufficiale de 4 marzo 2020, núm. 10.
} 
13. La Corte se ampara en el Dictamen del TEDH de 10 de abril de $2019^{18}$, en el que se ha establecido que el derecho al respeto de la vida privada ${ }^{19}$ del niño nacido por gestación subrogada requiere que los Estados prevean la posibilidad de reconocer su relación de filiación con la madre intencional no biológica, indicada como madre legal en el acta de nacimiento legalmente emitida en el extranjero.

De hecho, según el TEDH, la imposibilidad general y absoluta de obtener el reconocimiento de la relación entre un niño nacido por medio de un contrato de gestación subrogada celebrado en el extranjero y la madre comitente es incompatible con el interés superior del niño, que exige, como mínimo, que cada situación sea examinada a la vista de las circunstancias particulares del asunto.

14. En esta línea, el Tribunal reconoce también que el interés superior del niño no implica simplemente el respeto de su derecho a la vida privada, sino que incluye otros aspectos esenciales que no necesariamente pesan a favor del reconocimiento de una relación jurídica paternofilial con la madre comitente, como la protección contra los riesgos de abuso que implican los acuerdos de gestación subrogada $^{20}$ y la posibilidad de conocer el origen de la persona ${ }^{21}$.

Sin embargo, es muy importante para el menor que la incertidumbre sobre la relación jurídica con la madre comitente sea lo más breve posible, puesto que, mientras tanto, aquél se encontrará en una situación vulnerable en lo que se refiere a varios aspectos de su derecho al respeto de la vida privada. Sobre este punto, el TEDH sostiene que la falta de reconocimiento en el derecho interno de la relación entre la madre comitente y el niño es perjudicial para éste, ya que lo coloca en una situación de inseguridad jurídica con respecto a su identidad en la sociedad ${ }^{22}$.

15. No obstante, esto no implica necesariamente la trascripción del acta judicial extranjera en el Registro civil, pudiendo obtenerse el mismo resultado por otras vías, como la adopción por parte de la madre intencional ${ }^{23}$, con tal de que se garantice la efectividad y la rapidez de su realización ${ }^{24}$, de conformidad con el interés superior del menor, siempre y cuando dicha relación se haya convertido en una "realidad práctica". De hecho, el Tribunal considera que "el artículo 8 del Convenio no impone a los Estados la obligación general de reconocer ab initio una relación paterno-filial entre el niño y la madre comitente. Lo que el interés superior del niño -que debe ser evaluado principalmente en concreto y no en abstracto- requiere es que el reconocimiento de esa relación, legalmente establecida en el extranjero, sea posible como máximo cuando se haya convertido en una realidad práctica" ${ }^{" 25}$.

18 "Dictamen en relación con el reconocimiento en el Derecho interno de una relación jurídica paterno-filial entre un niño nacido mediante gestación subrogada en el extranjero y la madre comitente Solicitado por el Tribunal de Casación francés", Demanda núm. P16-2018-001, Estrasburgo 10 de abril de 2019 (ECHR 132, 2019).

${ }^{19}$ Cfr. art. 8 del Convenio Europeo para la Protección de los Derechos Humanos y de las Libertades Fundamentales y art. 7 de la Carta de los Derechos Fundamentales de la Unión Europea.

${ }^{20}$ Véase Paradiso y Campanelli, v. Italia, $\mathrm{n}^{\mathrm{o}}$ 25358/12, de 24 de enero de 2017, § 202.

${ }^{21}$ Véase, por ejemplo, Mikulić v. Crocia, no. 53176/99, §§ 54-55, TEDH 2002-I.

${ }^{22}$ Vid. párr. 40 del Dictamen. En el mismo sentido, cfr. Mennesson v. France, n ${ }^{\circ} 65192 / 11$, TEDH 2014, § 96 y Labassee c. Francia, ${ }^{\circ} 65941 / 11$, de 26 de junio de 2014, § 75).

${ }^{23}$ Lit.: "En una situación en la que, como en el escenario descrito en las preguntas planteadas por el Tribunal de Casación, un niño nacido en el extranjero a través de un acuerdo de gestación subrogada y concebido utilizando los gametos del padre comitente y de una tercera donante, y en la que la relación jurídica paterno-filial con el padre comitente ha sido reconocida en la legislación nacional:1. El derecho del niño al respeto de su vida privada en el sentido del artículo 8 del Convenio exige que la legislación nacional prevea la posibilidad de reconocer una relación jurídica paterno-filial con la madre comitente, designada en el certificado de nacimiento legalmente establecido en el extranjero como "madre legítima"; 2 . El derecho del niño al respeto de su vida privada en el sentido del artículo 8 del Convenio no exige que dicho reconocimiento adopte la forma de inscripción en el registro de nacimientos, matrimonios y defunciones de los datos de la partida de nacimiento legalmente establecida en el extranjero; pueden utilizarse otros medios, como la adopción del niño por la madre comitente, siempre que el procedimiento establecido por la legislación nacional garantice que pueda ser aplicado con prontitud y eficacia, de conformidad con el interés superior del niño".

24 "Dado el margen de apreciación de que disponen los Estados en cuanto a la elección de los medios, las alternativas al registro, en particular la adopción por parte de la madre comitente, pueden considerarse aceptables en la medida en que el procedimiento establecido por la legislación nacional garantice que puedan aplicarse con prontitud y eficacia, de conformidad con el interés superior del niño" (párr. 55 del Dictamen)

${ }^{25}$ Cfr. párr. 52 del Dictamen. 
16. Respecto de estas conclusiones del TEDH, la Corte de Casación identifica dos perfiles de conflicto con la situación actual del "diritto vivente" en Italia. En primer lugar, se evidencia que la atribución a la prohibición de la maternidad subrogada del estatuto de "principio de orden público internacional", que prevalece a priori sobre el interés del menor por efecto de una elección hecha por el legislador italiano en vía general y abstracta respecto de la evaluación del caso concreto, constituye una medida que afecta negativamente a los nacidos por gestación subrogada, pues tiene el efecto de negar los derechos inviolables relacionados con la identidad personal del menor y su pertenencia a la familia de origen, reconocida en el acta de nacimiento legalmente formado en el país de nacimiento. En particular, según la Corte, la primacía del interés del menor impide que el legislador pueda comprimir dicho interés de forma general y abstracta, determinando así un debilitamiento por ley del derecho al reconocimiento del status filiationis legítimamente adquirido en el país extranjero de nacimiento.

17. En segundo lugar, se evidencia la carencia, en el ordenamiento interno, de instrumentos alternativos a la transcripción en el Registro civil que puedan proporcionar al menor una justa tutela, reconociéndole su status filiationis sin dar lugar a la prolongación de una situación de inseguridad jurídica en cuanto a la relación paterno-filial del menor. Sobre este punto, la Corte de Casación considera en particular que el instrumento de la "adopción en casos especiales" de conformidad con el art. 44, letra d) de la ley núm. 184/1983 es una institución que no es en absoluto apta para garantizar la eficacia y celeridad de la atribución de la filiación, siendo éstas las que el TEDH considera como condiciones esenciales para calificar a esa modalidad alternativa a la transcripción en el Registro, de respetuosa del derecho a la protección de la vida privada y familiar del menor.

\section{La decisión de la Suprema Corte Constitucional y sus fundamentos}

18. Ante esta cuestión de legitimidad constitucional, la Suprema Corte Constitucional italiana, en la Sentencia 33/202126, ha considerado inadmisible la censura del "diritto vivente" en la parte en que califica la prohibición sancionada penalmente de la gestación por sustitución como "principio de orden público" colocado para la protección de valores fundamentales, incluida, en particular, la dignidad humana de la mujer embarazada.

19. La decisión se funda en que la misma Corte Constitucional ya se ha expresado en términos similares señalando que la práctica de la maternidad subrogada ofende intolerablemente la dignidad de la mujer y socava profundamente las relaciones humanas ${ }^{27}$, y que los acuerdos de gestación por sustitución conllevan el riesgo de explotar la vulnerabilidad de las mujeres que se encuentran en situaciones sociales y económicas desfavorecidas. Estas consideraciones encuentran apoyo en la condena de "cualquier forma de maternidad subrogada con fines comerciales" expresada por el Parlamento Europeo en su Resolución de 13 de diciembre de 2016 sobre la situación de los derechos fundamentales en la Unión Europea en 2015 28 .

20. Por otro lado, en relación con el interés del menor, según la Corte Constitucional no puede considerarse que éste prevalezca automáticamente sobre cualquier otro interés contrapuesto. De hecho, a pesar de su importancia, que se desprende de la frecuente insistencia en la "preeminencia" de este interés y del especial "peso" que se le otorga, debe recordarse que todos los derechos fundamentales protegidos por la Constitución se encuentran en relación de integración mutua y, por lo tanto, no es posible atribuir a uno de ellos la primacía absoluta sobre los demás ${ }^{29}$ con respecto a situaciones jurí-

\footnotetext{
${ }^{26}$ Cfr. Corte Cost., sent. núm. 33 de 2021, Gazzetta Ufficiale de 10 marzo 2021, núm. 10.

${ }^{27}$ Cfr. Corte Cost., sent. núm. 272 de 2017, cit.

28 2016/2009-INI, párr. 82.

${ }^{29}$ La Corte, en su sentencia n. 85 de 2013 (Gazzetta Ufficiale de 15 mayo 2013, núm. 20) habla de un "derecho tirano". Literalmente: "se così non fosse, si verificherebbe l'illimitata espansione di uno dei diritti, che diverrebbe "tiranno" nei confronti delle altre situazioni giuridiche costituzionalmente riconosciute e protette".
} 
dicas reconocidas y protegidas constitucionalmente, que constituyen, en su conjunto, expresión de la dignidad de la persona.

21. Los intereses del menor deberán entonces ser equilibrados, a la luz del criterio de proporcionalidad, con el objetivo legítimo perseguido por el ordenamiento de desincentivar el recurso a la gestación por sustitución, penalmente sancionado por el legislador. Trátase de un balance del que se han hecho cargo las Secciones Unidas de la Corte de Casación, negando la transcripción de la orden de un tribunal extranjero, en la parte en la que también atribuye la condición de progenitor al miembro de la pareja que participó en la gestación por sustitución sin aportar sus propios gametos.

22. La Corte Constitucional considera legítima la decisión de no autorizar la transcripción de la orden del tribunal extranjero, siempre y cuando esté asegurada la protección del interés del menor al reconocimiento legal de su relación con ambos miembros de la pareja comitente (presuponiendo que uno de ellos sea progenitor biológico), si éstos cuidaron del menor, ejercitando de facto la responsabilidad parental.

Cualquier solución que prive al menor de toda oportunidad de obtener un tal reconocimiento, incluso ex post y tras un control por parte del tribunal, acabaría, según la Corte, instrumentalizando a la persona del menor en aras de desincentivar el recurso a la práctica de la maternidad subrogada.

23. A pesar de declarar la cuestión de legitimidad constitucional inadmisible, considerando que en el estado actual no puede intervenir, estando obligada a respetar la discrecionalidad legislativa, la Corte ha remarcado la necesidad de una intervención del legislador para adecuar el derecho vigente a las exigencias de tutela de los intereses de los niños nacidos por esta técnica, garantizando un proceso de adopción rápido y efectivo, que reconozca la plenitud del vínculo de filiación entre el adoptante y el adoptado, una vez comprobada su correspondencia con el interés superior del niño.

\section{Consideraciones críticas}

\section{Las cuestiones controvertidas}

24. A la luz del estado actual de la jurisprudencia sobre este tema, me parece importante destacar algunas cuestiones controvertidas que podrían derivar del planteamiento descrito.

Se trata, in primis, del mismo concepto de orden público internacional, tal y como lo ha entendido la Corte de Casación en Secciones Unidas ${ }^{30}$, comprensivo de leyes ordinarias e interpretaciones jurisprudenciales que forman el llamado "diritto vivente" y de su aplicación al caso concreto.

En segundo lugar, es necesario evidenciar la complejidad del juicio discrecional del juez acerca de la individuación del interés superior del menor en el caso concreto, al fin de operar el necesario balance de ese interés con otros valores y derechos fundamentales que constituyen el orden público internacional y tomar las decisiones acerca de su status filiationis.

Un tercer punto está constituido por la dificultad del juicio acerca de la existencia de una relación paternofilial de facto entre el progenitor intencional y el menor, que pueda considerarse como concreta y consolidada, y cuyo reconocimiento y mantenimiento corresponda realmente al interés superior del menor, al fin de poder garantizar al niño la satisfacción de su interés a una continuidad y estabilidad afectiva, relacional y familiar.

Un cuarto y último punto está constituido por los límites del instituto de la "adopción en casos particulares", que la Corte de Casación en Secciones Unidas ha sugerido como solución para legalizar la situación de la paternidad intencional no biológica.

\footnotetext{
${ }^{30}$ Cass., Secc. unidas, 8 mayo 2019, núm. 12193, cit.
} 


\section{La individuación del concepto de orden público internacional y el "diritto vivente".}

25. Por lo que se refiere a la primera de las cuestiones planteadas, recordamos que la Corte de Casación ha venido a establecer un nuevo concepto de orden público internacional, que comprende - más allá de los principios fundamentales consagrados en la Carta Constitucional y en las fuentes internacionales y supranacionales- la ley ordinaria, como instrumento de actuación de los valores constitucionales y el "diritto vivente", entendido como la obra de interpretación realizada por la jurisprudencia constitucional y ordinaria, a través de la cual se ha llegado a la extrapolación de los principios fundamentales del ordenamiento jurídico.

26. En primer lugar, el concepto mismo de "diritto vivente", entendido como una de las fuentes primarias que contribuyen a construir el orden público internacional, conlleva a mi parecer unos cuantos problemas e incoherencias. De hecho, por la propia naturaleza de la obra interpretativa de los Tribunales, se trata de un derecho "vivo" y por eso continuamente "cambiante", lo cual en sí no es necesariamente un factor negativo, pues es deseable que el derecho evolucione siguiendo el desarrollo de la sociedad y de sus valores. Sin embargo, hay que considerar que se necesita también una cierta estabilidad con referencia a los valores individuados como "fundacionales" del orden público internacional.

27. Además, considero que el hecho de confiar a la obra interpretativa de la jurisprudencia la tarea de identificar tales principios fundamentales del ordenamiento jurídico puede ser relativamente incoherente si consideramos la notoria falta de uniformidad de las decisiones jurisprudenciales, especialmente sobre un tema tan complejo como el que nos atañe. El mismo juicio de constitucionalidad anteriormente analizado, propuesto con ordenanza del 29 de abril de 2020, por la sección primera civil de la Corte de Casación en contra de la Sentencia de la misma Corte en Secciones Unidas núm. 12193/2019, es un claro ejemplo de esta falta de uniformidad que presenta no sólo la jurisprudencia de mérito, sino también la de legitimidad, que en el caso italiano es representada por la Corte de Casación, y que notoriamente reviste una función nomofiláctica. Esta postura nos lleva inevitablemente hacia un concepto de orden público cuyo contenido es relativo y variable.

\section{El interés superior del menor en el caso concreto.}

28. Respecto de la segunda cuestión, es decir, la individuación por parte del juez del interés superior del menor en cada caso concreto, se pueden evidenciar numerosos aspectos críticos.

En primer lugar, se trata de un concepto jurídico indeterminado, con lo cual la discrecionalidad del juez a la hora de su concreción es notablemente elevada. De hecho, este interés se califica como una cláusula general, a la que el juez debe referirse obligatoriamente en la búsqueda del resultado óptimo de justicia en el caso concreto, operación hermenéutica aún más delicada cuando se destacan los derechos fundamentales y las cuestiones existenciales de la persona ${ }^{31}$.

29. En segundo lugar, y no menos importante, el interés superior del menor no es un título de determinación de la filiación, y tampoco puede erigirse en un criterio de transgresión normativa ${ }^{32}$. De hecho, no se protegería el interés superior del menor estableciendo una filiación que contradijera los criterios previstos en la ley para su determinación; en particular supondría un perjuicio para el menor

\footnotetext{
${ }^{31}$ A. SASSI, "Azioni ablative di stato e interesse del figlio alla continuità affettiva", artículo en curso de publicación en Diritto e Processo, año 2020. Cfr. también A. Palazzo, "La filiazione", en Trattato di Diritto Civile e Commerciale Cicu-Messineo, $2^{\mathrm{a}}$ ed., Milano, 2013, pp. 251 y ss. y 532 y ss.; A. Sassi, F. Scaglione, S. Stefanelli, "La filiazione e i minori”, en R. Sacco (Dir.), Trattato di Diritto Civile. Sacco, $2^{\mathrm{a}}$ ed., Torino, 2018, pp. 3 y ss., 221 y ss., 351 y ss., 515 y ss.; M. DI MASI, L'interesse del minore. Il principio e la clausola generale, Napoli, 2020, pp. 99 y ss.

${ }^{32}$ J. Nanclares Valle, "El interés superior del menor en la gestación por sustitución", Revista General de Derecho Constitucional, núm. 31, enero 2020, pp. 11 y ss.
} 
si se admitiera la determinación de la filiación con base en lo dispuesto en un contrato de maternidad subrogada, siendo aquello contrario a su dignidad, al convertirlo en objeto de tráfico mercanti1 ${ }^{33}$.

Por lo tanto, "no procede acudir al concreto interés superior del menor para lograr la atribución de la paternidad o maternidad obviando los medios legales de determinación previstos", ni para atribuir eficacia a unas resoluciones extranjeras contrarias a las normas sustantivas y a los principios y valores elementales que informan el ordenamiento jurídico interno ${ }^{34}$.

\section{El balance del interés superior del menor con los demás derechos fundamentales}

30. La protección del interés superior de menor, puesto que no se trata de un concepto absoluto ni ilimitado, sólo puede llegar hasta donde lo permite la ley, debiendo "ceder ante intereses jurídicamente más relevantes" 35 .

En este sentido, la Corte Constitucional considera que el interés superior del menor no tiene prevalencia absoluta sobre los demás derechos fundamentales tutelados por la Constitución, pues de lo contrario se produciría la expansión ilimitada de uno solo de los derechos, que se convertiría en "tirano" frente a otras situaciones jurídicas reconocidas y constitucionalmente protegidas, que constituyen, en su conjunto, expresión de la dignidad de la persona ${ }^{36}$.

Por lo tanto, el interés superior del menor se encuentra en una relación de integración recíproca con los demás valores y derechos fundamentales del ordenamiento jurídico, que en su conjunto constituyen el orden público internacional ${ }^{37}$.

32. En este contexto, se ha criticado especialmente la posición asumida por la Corte de Casación en Secciones Unidas cuando otorga a la prohibición de la gestación subrogada, contenida en la ley nacional, superioridad respecto del interés superior del menor ${ }^{38}$ : se ha considerado que "el interés del menor se ha degradado con respecto a los intereses de la comunidad" puesto que "el derecho a que se reconozca la condición de filiación legítimamente constituida en el extranjero se sitúa en un orden inferior con respecto al interés general de los ciudadanos a que se observe la prohibición de la gestación subrogada" 39 .

33. Sin embargo, considero que no se trata realmente de un balance entre el interés superior del menor y la prohibición en sí de la gestación subrogada, sino que más bien, siguiendo la letra de la Sentencia citada, se trata de considerar los valores fundamentales -como la dignidad de la mujer y la

\footnotetext{
${ }^{33}$ En este sentido, cfr. también la STS español de 6 de febrero de 2014 (RJ 2014|833)

${ }^{34}$ J. Nanclares VAlLe, ob. $y$ loc. cit.

${ }^{35}$ A.J. Vela SÁnChEz, "El interés superior del menor como fundamento de la inscripción de la filiación derivada del convenio de gestación por encargo", Diario La Ley, 8162 (2013), La Ley 5167/2013, p. 6.

${ }^{36}$ Cfr. Corte Cost., sent. núm. 33 de 2021, Gazzetta Ufficiale de 10 marzo 2021, núm. 10 y Sentencia núm. 85 de 2013, Gazzetta Ufficiale de 15 mayo 2013, núm. 20.

${ }^{37}$ Sobre el punto, cfr. las interesantes reflexiones de J. NANCLAReS VALLE, ob. y loc. cit.: "En materia de gestación por sustitución se ha querido contraponer el orden público al interés superior del menor (...). En realidad, el interés superior del menor forma parte del orden público, en cuanto que principio esencial del Derecho de familia, y su defensa pasa por el respeto de la dignidad del hijo y de sus derechos fundamentales, lo cual exige no ser objeto de contrato, que no sea posible la libre disposición sobre su estado civil y que se apliquen las normas sobre determinación de la filiación (tanto del Código civil como de la Ley 14/2006) y sobre constitución de la adopción, normas que persiguen precisamente la satisfacción de ese interés superior y que establecen los cauces legales para conseguirla".

${ }^{38}$ Cfr. Cass., Secc. Unidas, 8 mayo 2019, núm. 12193, cit.: "Il riconoscimento dell'efficacia del provvedimento giurisdizionale straniero con cui sia accertato il rapporto di filiazione tra un minore nato all'estero mediante il ricorso alla maternità surrogata ed il genitore d'intenzione munito della cittadinanza italiana trova ostacolo nel divieto di cui all'art. $12,6^{\circ}$ comma, 1. n. 40 / 2004, qualificabile come principio di ordine pubblico, in quanto posto a tutela di valori fondamentali, quali la dignità umana della gestante e l'istituto dell'adozione; la tutela di tali valori, non irragionevolmente ritenuti prevalenti sull'interesse del minore, nell'ambito di un bilanciamento effettuato direttamente dal legislatore, al quale il giudice non può sostituire la propria valutazione, non esclude peraltro la possibilità di conferire rilievo al rapporto genitoriale, mediante il ricorso ad altri strumenti giuridici, quali l'adozione in casi particolari, prevista dall'art. 44, $1^{\circ}$ comma, lett. d), 1. n. 184 / 1983".

${ }^{39}$ A. VAlongo, "Gestazione per altri...", cit., pág. 550.
} 
protección de la infancia a través del instituto de la adopción - que esa misma prohibición está dirigida a tutelar y que realmente constituyen un contrapeso para el reconocimiento automático de una relación de filiación no biológica originada por gestación subrogada y formalizada en el extranjero ${ }^{40}$.

Además, la Corte de Casación no excluye la posibilidad de recurrir a otras soluciones jurídicas para obtener la formalización de la relación paternofilial con el progenitor intencional, soluciones que, por otro lado, la Corte Constitucional razonablemente sugiere ampliar y mejorar.

\section{La cuestión del status filiationis del niño}

34. Reconocida la complejidad del juicio discrecional del juez a la hora de concretar el interés superior del menor en cada caso, y la necesidad de un balance de ese interés con otros derechos fundamentales que constituyen el orden público internacional, vamos a centrarnos en la decisión acerca del status filiationis del niño.

35. En este contexto, es oportuno distinguir entre la aplicación de los principios de orden público internacional, por un lado, a la práctica en sí de la gestación subrogada y, por otro lado, a las situaciones jurídicas subjetivas del niño, en particular respecto de su derecho a adquirir un status filiationis que respete en la medida de lo posible su interés superior a tener una estabilidad afectiva, relacional y familiar y a que se reconozca su propia identidad ${ }^{41}$. De ahí que, en relación con la práctica de la gestación subrogada, la prohibición debe considerarse plenamente operativa, con la consiguiente ineficacia, por contraria al orden público, de cualquier disposición extranjera que reconozca los derechos vinculados a ella como, por ejemplo, la solicitud de la remuneración pactada o el cumplimiento de las obligaciones previstas por el contrato de gestación por sustitución.

36. Viceversa, el reconocimiento de las situaciones jurídicas subjetivas vinculadas a la condición de hijo, ya que es un derecho fundamental reconocido expresamente por la Constitución italiana (artículos 30 y 31) y por el Carta de los Derechos Fundamentales de la Unión Europea (artículo 24), debe ser visto exclusivamente desde la perspectiva del niño, sin importar el origen de su filiación ${ }^{42}$.

Los derechos de los nacidos que pertenecen al orden público constitucional no pueden estar condicionados por la circunstancia de que la gestación haya tenido lugar de manera contraria al orden público discrecional ${ }^{43}$. En otras palabras, el discrimen está en el interés del niño y en sus derechos inalienables como persona humana ${ }^{44}$ : "si consideráramos lo contrario, confundiendo los dos perfiles, llegaríamos a la absurda consecuencia de discriminar al nacido en la atribución de la condición de niño

${ }^{40}$ Sobre esta cuestión, M. BIANCA, "La tanto attesa decisione delle Sezioni Unite. Ordine pubblico versus superiore interesse del minore", en Familia: rivista di diritto della familia e delle successioni in Europa, 2019, 3, pp. 370 y 382-385 expresa su desacuerdo con la consideración de que el orden público internacional pueda ponerse "en competición" con el best interest del menor, puesto que el mismo interés superior del menor, a pesar de su indeterminación, constituye un principio de orden público.

${ }^{41}$ Cfr. A. Sassi, S. Stefaneldi, "Ordine pubblico differenziato e diritto allo stato di figlio nella g.p.a" en Articolo29: La trascrizione dei certificati di nascita fra sindaci, giudici e Sezioni unite: dieci brevi contributi per un dibattito attuale, pp. 8-9.; V. BARBA, "Note minime sull'ordine pubblico internazionale", en Articolo29: La trascrizione dei certificati di nascita fra sindaci, giudici e Sezioni unite: dieci brevi contributi per un dibattito attuale, p. 10; A. VALONGO, "Gestazione per altri e ordine pubblico internazionale. La c.d. “filiazione omogenitoriale”, en Giurisprudenza italiana, 2020, 172 (3), pp. 543-558.

${ }^{42}$ Cfr. A. Sassi, S. Stefanelli, "Nascita da gestazione per altri e diritto allo status (nota a Cass., Sez. un.

civili, 8 maggio 2019, n. 12193)", en Diritto e Processo, 2019, pp. 507 y 508.

${ }^{43}$ Para la distinción entre orden público constitucional y orden público discrecional, cfr. S A. SASSI, S. StefanelLI, "Nascita da gestazione per altri...", cit., p. 507. Sobre el punto, se expresa también, entre otros: G. FerRando, "I bambini prima di tutto. Gestazione per altri, limiti alla discrezionalità del legislatore, ordine pubblico", en La nuova giurisprudenza civile commentata, 2019, 35 (4), p. 820: "Una cosa è tuttavia la sanzione per la condotta dei genitori, altra cosa lo status del figlio (...). Non ritengo decisivo il fatto che la nascita sia avvenuta grazie a tecniche vietate dall'ordinamento interno. E neppure il fatto che alla GPA, si attribuisca un "elevato grado di disvalore". Si deve infatti tenere presente che, in materia di status, il legislatore ha definitivamente abbandonato ogni logica sanzionatoria: se tutela dei diritti del bambino costituisce fine primario dell'ordinamento, allora non può essere sacrificata per condannare il comportamento dei genitori".

${ }^{44}$ V. BARBA, "Note minime ..." cit., p. 10. 
según las circunstancias del nacimiento y la forma de gestación" "45. Así que el hecho de que el nacimiento se deba a una conducta reprobada por la ley con el uso de sanciones penales no debería impedir que se constituya legalmente el status filiationis del niño ${ }^{46}$.

37. En otras palabras, no se les puede privar a los niños nacidos por sustitución de maternidad de la posibilidad de que se les reconozca un status filiationis (lo que es indudable, como se afirmó en el caso Mennesson c. Francia), por ilegalmente que hayan obrado los comitentes y siempre que uno de ellos sea el progenitor biológico; sin embargo, desplazándose el centro de gravedad de la discusión al tema de cómo y con qué criterios se establece esa filiación, sí es admisible no convalidar sin más las resoluciones extranjeras, y aplicar el orden público para actuar de "filtro", de modo que se reconozca como progenitor quien biológicamente lo sea y que el mero progenitor de intención se tenga que reconducir a los cauces previstos por el derecho italiano. Cauces sin duda establecidos en aras del interés del menor.

\section{La existencia de una relación paternofilial de facto consolidada entre el progenitor intencional y el menor}

38. Cabe también señalar la complejidad del juicio acerca de la existencia de una relación paternofilial de facto entre el progenitor intencional y el menor, que debe poderse calificar como concreta y consolidada. En este juicio normalmente interviene el factor temporal, pues la cuestión principal radica en la identificación del marco de tiempo adecuado para estabilizar el vínculo afectivo entre el menor y el padre de intención ${ }^{47}$.

39. El legislador ha considerado adecuado el término de un año para proteger la afectividad mutua consolidada, aunque con efectos limitados a las acciones privativas del estado de filiación. En efecto, el plazo para impugnar la filiación es de un año desde que el progenitor que no fue el autor de la procreación descubre su impotencia o el adulterio de la esposa: transcurrido ese plazo, en aras del interés del hijo, la acción paterna caduca.

El término anual, además, suele aparecer en el derecho de familia a los efectos de la consolidación de los efectos (véanse, en el matrimonio, los últimos párrafos de los artículos 119, 120, 122 y 123 del Código Civil italiano); además, la protección de la afectividad consolidada está en el centro de la reciente intervención del legislador en materia de adopción ${ }^{48}$.

\footnotetext{
${ }^{45}$ A. SASSi, S. STEFAnelli, "Ordine pubblico differenziato...” cit., pp. 7 y ss.

${ }^{46}$ G. Ferrando, "I bambini prima di tutto..." cit., p. 820.

${ }^{47}$ Sobre la relación paterno-filial de facto, vid. Corte EDU, 28 giugno 2007, Wagner e J.M.W.L. c. Lussemburgo, en Famiglia, persone e successioni, 2007, p. 956; Corte EDU, 26 giugno 2014, Mennesson et al. c. Francia, en Foro italiano, 2014, IV, c. 561; C. CAMPIGLIO, "Il diritto all'identità personale del figlio nato all'estero da madre surrogata (ovvero, la lenta agonia del limite dell'ordine pubblico)", Nuova giurisprudenza civile commentata, 2014, I, p. 1123. Sobre la consolidacion de la afectividad, cfr. Corte EDU, 27 gennaio 2015, Paradiso e Campanelli c. Italia, en Foro italiano, 2015, IV, c. 117; A. SCHUSTER, "Gestazione per altri e Conv. eur. dir. uomo: l'interesse del minore non deve mai essere un mezzo, ma sempre solo il fine del diritto" en Nuova giurisprudenza civile commentata, 2015, I, p. 828; L. LenTI, "Ancora sul caso Paradiso \& Campanelli c. Italia: la sentenza della Grande Camera", ivi, 2017, p. 501; A. VIVIANI, "Paradiso e Campanelli di fronte alla Grande Camera: un nuovo limite per le «famiglie di fatto»?", Genius, 1/2017, pp. 78 y ss.; E. FAlLetTI, "Vita familiare e vita privata nel caso Paradiso e Campanelli di fronte alla Grande Camera della Corte di Strasburgo", Famiglia e diritto, 2017, pp. 729 y ss.

${ }^{48}$ Cfr. artículo 4, apartados 5 bis y 5 ter, Ley 4 mayo 1983, n. 184, "sul diritto alla continuita' affettiva dei bambini e delle bambine in affido familiare", introducidos por la Ley n. 173/2015 de 19 octubre ("Modifiche alla legge 4 maggio 1983, n. 184, sul diritto alla continuita' affettiva dei bambini e delle bambine in affido familiare", Gazzetta Ufficiale, Serie Generale n. 252 del 29 octubre 2015): "5 -bis. Qualora, durante un prolungato periodo di affidamento, il minore sia dichiarato adottabile ai sensi delle disposizioni del capo II del titolo II e qualora, sussistendo i requisiti previsti dall'articolo 6, la famiglia affi dataria chieda di poterlo adottare, il tribunale per i minorenni, nel decidere sull'adozione, tiene conto dei legami affettivi significativi e del rapporto stabile e duraturo consolidatosi tra il minore e la famiglia affidataria"; "5 -ter. Qualora, a seguito di un periodo di affidamento, il minore faccia ritorno nella famiglia di origine o sia dato in affidamento ad altra famiglia o sia adottato da altra famiglia, è comunque tutelata, se rispondente all'interesse del minore, la continuità delle positive relazioni socio-affettive consolidatesi durante l'affidamento".
} 
40. No obstante, en el caso de la gestación subrogada, considero que el plazo debería ser más amplio, para evitar que los retrasos burocráticos favorezcan la legalización indirecta de una situación antijurídica.

Además, la parte más difícil del juicio está constituida por determinar que el interés superior del menor se corresponde con el mantenimiento de esa relación, pues le garantiza continuidad y estabilidad afectiva.

41. La cuestión principal es con qué criterio valorará el juez que el progenitor intencional, individualmente o conjuntamente con su pareja (que podrá ser otro progenitor intencional, o - en su caso - progenitor biológico), constituye el sujeto más idóneo para cuidar del niño, puesto que el mero criterio temporal en este caso no podrá operar para justificar una situación ya creada y para legitimarla ex post en base a la consideración de que la situación "pseudo- familiar" se ha estabilizado y se ha consolidado en el tiempo. De lo contrario estaríamos ante una forma de "usucapión del estado civil de filiación", que sabemos que en sí es indisponible.

Tampoco podrá valer como criterio la simple voluntad de tener un hijo, manifestada a través del recurso a la práctica prohibida de la gestación subrogada.

No es de excluir, además, que el progenitor intencional pueda estar afectado por patologías incompatibles con el status quo, cuales la psicopatía u otros trastornos mentales que conlleven comportamientos violentos, o pueda haber sido con anterioridad condenado por pedofilia, o privado de la patria potestad sobre sus hijos biológicos por desatenderles completamente.

42. La Corte de Casación italiana reconoce la centralidad del interés del niño en mantener el status adquirido, incluso si se basa en la afectividad ${ }^{49}$, en el marco de la tutela de la salud psicofísica y de la identidad personal del menor, delineando una dicotomía entre filiación-título y filiación-relación ${ }^{50}$. En otras palabras, este nuevo sistema, basado en los principios de afectividad e identidad familiar consolidada, supera el principio de veracidad del status como expresión de un interés público absoluto.

43. Con esta nueva concepción, se elimina la centralidad del favor veritatis como criterio irreversible para la atribución de la paternidad y se da entrada a más criterios para identificar la paternidad, que tienen como referencia principal el interés del menor. Por lo tanto, el interés del menor puede concretarse mediante la constatación de la verdad biológica con efectos adquisitivos o privativos del status, $\mathrm{o}$, a la inversa, mediante la protección de la afectividad consolidada o del status existente ${ }^{51}$.

De ello se desprende que la estabilidad emocional del niño justifica el mantenimiento de un status falso cuando se considere que éste coincide con las necesidades existenciales del mismo ${ }^{52}$.

44. El legislador italiano ha previsto explícitamente la relevancia del derecho del menor a la continuidad afectiva, derecho que se implementa mediante la protección de las relaciones consolidadas $^{53}$.Así la Corte de Casación, en la "adopción en casos particulares" del hijo de la pareja homosexual

\footnotetext{
${ }^{49}$ Cfr., entre otras, la sentencia de la Corte Constitucional núm. 272 de 18 dicembre 2017, cit., comentada por A. SASSI, "Gestazione per altri e ruolo delle azioni di stato", en Diritto e processo, 2017, pp. 263-301.

${ }^{50}$ Cfr. A. Sassi, F. Scaglione, S. Stefanelli, "La filiazione e i minori”, cit., pp. 6 y ss.

${ }^{51}$ A. SASSI, "Azioni ablative di stato e interesse del figlio alla continuità affettiva", ob. y loc. cit. Cfr. Cass. de 15 junio 2017, n. 14878, que permitió, amparándose en el interés del niño, la transcripción del certificado de nacimiento formado en el extranjero también para la mujer que ni dio a luz ni proveyó los gametos. Comentan esta sentencia S. Stefanelli, "Riconoscimento dell'atto di nascita da due madri, in difetto di legame genetico con colei che non ha partorito", articolo29.it y M. FINOCCHIARO, "Quel «vizio» ricorrente di anticipare le scelte devolute al legislatore", Guida al diritto, 28/2017, p. 54.

${ }^{52}$ Cfr. Cass. de 24 febrero 2020, n. 4791: en este caso, la Corte considera que es prevalente el interés del niño a no perder el vínculo identitario con el progenitor que decide impugnar la filiación respecto del favor veritatis, pues se trata de un derecho constitucionalmente garantizado, que prevalece ante la búsqueda de la verdad genética, cuando el hijo, escuchado y con capacidad de discernimiento, se opone a un cambio existencial tan radical en su vida. Cfr. M. LABriola, "Impugnazione del riconoscimento per difetto di veridicità: il bilanciamento tra favor veritatis e intersse del figlio", Osservatorio dir. fam., 2/2020, p. 76.

${ }^{53}$ Cfr. artículo 4, apartados 5 bis y 5 ter, Ley 4 mayo 1983, n. 184, "sul diritto alla continuità affettiva dei bambini e delle bambine in affido familiare", introducidos por la Ley n. 173/2015 de 19 octubre, cit. Sobre la relevancia de la afectividad en
} 
("stepchild adoption"), reconoce el interés preeminente del menor a la constitución del estado de filiación con respecto a un sujeto hacia el cual se han establecido lazos afectivos fuertes y duraderos ${ }^{54}$.

Sin embargo, en el caso del recurso a la gestación subrogada, cuando no existe vínculo biológico entre el menor y la persona que ha asumido la responsabilidad, la Corte se ha mostrado más estricta, desconociendo en ocasiones la existencia de una afectividad consolidada y, por tanto, la vulneración del art. 8 de la Convención.

45. En efecto, una cosa es establecer un lazo de filiación vía adopción cuando la situación de origen es legal y otra muy distinta es hacer lo mismo cuando la situación es de partida ilegal.

Además, hay que destacar que el interés a la continuidad de las relaciones afectivas debe siempre ser examinado por el juez en el caso concreto, y seguramente debe excluirse cada vez que la relación del menor con el progenitor intencional conlleve la violación de valores constitucionalmente protegidos, in primis el de la dignidad y del respeto de la persona ${ }^{55}$.

De hecho, el argumento del gobierno italiano en el caso Paradiso Campanelli demuestra que no todo vale para originar una situación de facto que luego se convierta, vía afectividad consolidada, en de iure ${ }^{56}$.

\section{Los límites de la "adopción en casos particulares"}

46. Un último punto está constituido por los límites del instituto de la "adopción en casos particulares". Respecto de esto, hay que destacar que la llamada "adozione in casi particolari" no constituye, según el criterio predominante, un vínculo de parentesco con la familia del adoptante, puesto que el art. 55 de la Ley 184/1983 establece que se aplicarán a la adopción en casos particulares las normas contenidas en los arts. 293, 294, 295, 299, 300 y 304 del Código civil, que disciplinan la adopción de adultos. En particular, el art. 300 del Código civil italiano prevé que el adoptado conserva todos los derechos y deberes hacia su familia de origen y no adquiere lazos de parentesco con la familia del adoptante.

47. También la Corte Constitucional ${ }^{57}$ se ha expresado en este sentido, al señalar que la adopción en casos particulares constituye entre el niño y el progenitor "un vínculo jurídico (...) diferente al que se deriva del reconocimiento". Esto está confirmado por la disciplina del apellido del adoptado: de conformidad con el art. 299 del Código Civil italiano, mencionado en el art. 55 1. 184/1983, el menor conserva el apellido familiar que lleva, y antepone el del progenitor adoptante, mientras que en la adopción "plena" pierde, junto con los vínculos familiares, también el apellido original, para asumir el de los adoptantes.

48. Todo esto podría constituir un elemento desfavorable para el menor en su derecho al mantenimiento del status familiar legalmente constituido en el país extranjero. Además, este tipo de adopción condiciona el inicio del procedimiento a la solicitud del progenitor intencional, y supedita el pronunciamiento del título constitutivo del status filiationis al consentimiento del otro progenitor, en el ejercicio de su responsabilidad parental ${ }^{58}$, lo cual complica aún más su realización, sobre todo en caso de separación o desacuerdo de la pareja.

\footnotetext{
la dinámica familiar independientemente del título constitutivo cfr. Cass., Sez. un., 17 luglio 2014, n. 16379 y en doctrina A. Vesto, "La rilevanza del fattore temporale nella dinamica dei rapporti familiari", Diritto e Processo, 2014, pp. 13 ss.

${ }^{54}$ Cass., 22 giugno 2016, n. 12962, Foro italiano, 2016, I, c. 2342. Cfr. A. Spadafora, “Adozione, tutela dell'omogenitorialità e rischi di eclissi della volontà legislativa", en Giurisprudenza italiana, 2016, p. 2573; I. RiverA, "La sentenza della Corte di cassazione n. 21692/2016 e il superiore interesse del minore", Nuova giurisprudenza civile commentata, 2016, p. 1135; P. MoROZzo DELla RocCA, "Le adozioni in casi particolari ed il caso della stepchild adoption", en Corriere giuridico, 2016, p. 1203; S. Veronesi, "La Corte di cassazione si pronuncia sulla stepchild adoption", Famiglia e diritto, 2016, p. 1025.

${ }^{55}$ Cfr. A. Sassi, F. Scaglione, S. Stefanelli, "La filiazione e i minori”, cit. p. 537.

${ }^{56}$ V. Paradiso y Campanelli, v. Italia, cit.

${ }^{57}$ Corte Cost., sent. 272/2017, cit.

${ }^{58}$ Cfr. Art. 46 1. n. 184/1983.
} 
Además, las disposiciones mencionadas plantean un problema de coordinación con las previstas tras la Ley 219/2012 $2^{59}$ sobre el status único del niño y, en particular, con la nueva formulación del art. 74 del Código Civil italiano que, al crear un estado único de filiación, ha dado lugar a un vivo debate sobre la relación con la adopción en casos especiales ${ }^{60}$.

\section{Conclusiones}

49. A la luz del estado actual de la jurisprudencia sobre este tema, los puntos fundamentales a destacar son los siguientes.

En primer lugar, siguiendo las indicaciones del TEDH, Italia no puede ser obligada a reconocer automáticamente la relación paternofilial del progenitor intencional del menor nacido por maternidad subrogada, sino que será el juez quien deberá considerar caso por caso e individuar en concreto la existencia de una relación paterno-filial que se haya convertido en una realidad práctica.

50. En segundo lugar, la decisión de la Corte Constitucional, en la reciente Sentencia 33/2021, al cerrar el juicio de legitimidad constitucional propuesto por la Sección Primera Civil de la Corte de Casación, considera legítima la decisión de no autorizar la transcripción de la orden del tribunal extranjero en la parte en que atribuye al progenitor intencional no biológico la condición de progenitor legal del niño nacido por maternidad subrogada, y entiende como incensurable la calificación de "principio de orden público" atribuida a la prohibición de la gestación por sustitución.

51. Sin embargo, la Corte remarca, al mismo tiempo, la exigencia de asegurar al menor el reconocimiento legal de su relación con los progenitores de intención, tras un juicio que verifique en concreto la existencia de una relación paternofilial consolidada que coincida con los intereses del niño.

A tal efecto, la Corte Constitucional invita al legislador a una adecuación del derecho vigente a las exigencias de tutela de los intereses de los niños nacidos por maternidad subrogada, en el contexto del difícil equilibrio entre el objetivo legítimo de desincentivar el recurso a esta práctica y la necesidad imperiosa de garantizar el respeto de los derechos de los menores.

Dicha exigencia deberá garantizarse mediante la previsión de un procedimiento de adopción eficaz y rápido, que reconozca la plenitud del vínculo de filiación entre el adoptante y el adoptado, cuando haya sido comprobada su correspondencia con los intereses del niño.

52. Finalmente, las principales cuestiones problemáticas que surgen del marco jurídico descrito son principalmente tres: la aplicación al caso concreto de los principios de orden público internacional y su compatibilidad con la tutela del interés superior del menor; el juicio acerca de la existencia entre el progenitor intencional y el menor de una relación paterno-filial de facto consolidada y merecedora de reconocimiento legal por corresponder realmente al interés superior del menor; y, finalmente, la cuestión de los límites de las soluciones jurídicas actuales, en particular del instituto de la "adopción en casos particulares"

\footnotetext{
${ }^{59}$ Se trata de la Ley 10 diciembre 2012, n. 219, Gazzetta Ufficiale n. 293 del 17 diciembre 2012, que elimina del ordenamiento jurídico las distinciones residuales entre hijos legítimos e hijos naturales, afirmando el principio de la unicidad de la condición jurídica de los hijos. Recordamos que ya la ley n. 184 de 1983, Gazzetta Ufficiale n.133 de 17 mayo 1983, había igualado la posición del hijo adoptivo al estado de hijo nacido del matrimonio.

${ }^{60}$ Sobre este punto, cfr. Tiziana Montecchiari, "Adozione in casi particolari: la svolta decisiv|a della Suprema Corte di Cassazione per single e coppie di fatto", Diritto di Famiglia e delle Persone (Il), fasc.4, 2019, pp. 1722 y ss.
} 